\title{
The effect and safety of ozone autohemotherapy combined with pharmacological therapy in postherpetic neuralgia
}

This article was published in the following Dove Press journal: Journal of Pain Research

\author{
Bin $\mathrm{Hu}^{1, *}$ \\ Jie Zheng ${ }^{2, *}$ \\ Qing Liu' \\ Yunkuan Yang' \\ Ying Zhang ${ }^{2}$
}

'Department of Pain Management, The Affiliated Traditional Chinese Medicine Hospital of Southwest Medical University, Luzhou, Sichuan, People's Republic of China; ${ }^{2}$ Department of Anesthesiology, the Affiliated Traditional Chinese Medicine Hospital of Southwest Medical University, Luzhou, Sichuan, People's Republic of China

*These authors contributed equally to this work
Correspondence: Qing Liu Department of Pain Management, The Affiliated Traditional Chinese Medicine Hospital of Southwest Medical University, No. 182, Longmatan District, Chunhui Road, Luzhou, Sichuan, People's Republic of China

Email 15328408055@163.com
Introduction: We investigated the effect and safety of ozone autohemotherapy combined with pharmacological therapy in postherpetic neuralgia (PHN).

Methods: Ninety-eight patients with PHN were enrolled in this study and randomly divided into a pharmacological therapy group and ozone autohemotherapy group (49 patients in each group). The PHN patients in the pharmacological therapy group were administered pharmacological therapy for 2 weeks, whereas PHN patients in the ozone autohemotherapy group were given ozone autohemotherapy $(200 \mathrm{~mL}$ blood from patients, the concentration of medical ozone was set as $30 \mu \mathrm{g} / \mathrm{mL}$ using an ozone medical apparatus, $40 \mathrm{~mL}$ medical ozone was incubated in $200 \mathrm{~mL}$ autologous blood for 3-5 minutes) combined with pharmacological therapy for 2 weeks. The Visual Analog Scale (VAS), the 50\% VAS reduction in the initial value, McGill Pain Questionnaire (MPQ), the Patients' Global Impression of Change (PGIC) scale, and the World Health Organization Quality of Life (WHOQOL-BREF) instrument were used to evaluate the outcomes of all PHN patients before therapy and at 1 week, 1 month, and 3 months after therapy. Results: Forty-five patients in the pharmacological therapy group and 47 patients in the ozone autohemotherapy group completed the study. Compared with before therapy, the two groups showed significant improvements in VAS, MPQ, PGIC, and WHOQOL-BREF scores after therapy $(P<0.05)$. Moreover, compared with the scores of the pharmacological therapy group, the ozone autohemotherapy group's scores were significantly improved in the VAS, MPQ, PGIC, and WHOQOL-BREF as well as the 50\% VAS reduction of the initial value after therapy $(P<0.05)$. Finally, there were no statistically significant differences in adverse effects between groups after therapy $(P>0.05)$.

Conclusion: The results of this study demonstrated that ozone autohemotherapy combined with pharmacological therapy was superior to isolated pharmacological therapy in patients with PHN and was an effective and safe way to relieve PHN.

Keywords: ozone autohemotherapy, pharmacological therapy, clinical trial, postherpetic neuralgia

\section{Introduction}

Patients with postherpetic neuralgia (PHN) suffer from persistent and severe breakthrough pain, which may arise from nerve changes due to virus infection or immune response. ${ }^{1} \mathrm{PHN}$ results from injury to the nervous system caused by varicella zoster virus (VZV) during infection. ${ }^{2} \mathrm{PHN}$ is one of the most common types of neuropathic pain (NP) syndrome and is characterized by pain. ${ }^{3}$ Patients who recover from herpes zoster rash may be afflicted with months and years of pain. ${ }^{4}$ Some studies have reported that compared with other types of pain, PHN is characterized by severe pain and severe harm to the patient's quality of life. ${ }^{5}$ In PHN, NP derived from previous VZV infection 
can last for $1-12$ months, ${ }^{6}$ and some studies have reported that this pain can last for 3 months in $21 \%$ of patients, 6 months in $9 \%$ of patients, and 12 months in $6 \%$ of patients, despite early drug therapy. ${ }^{7,8}$ In recent years, the concept of PHN therapy has focused on systemic antiviral drug therapy as well as pain management and topical treatment. ${ }^{9}$

Ozone is a molecule composed of three oxygen atoms and a component of the atmosphere in nature, which has a strong oxidizing action. Ozone has a high-energy, variable molecular structure under normal temperature and is quickly and spontaneously decomposed into $\mathrm{O}_{2}$ and a single oxygen atom $(\mathrm{O})$. It has strong activity in oxidation and a strong bactericidal effect on bacteria and viruses. ${ }^{10,11}$ Ozone therapy inactivates bacteria by disrupting their cell envelope through oxidation of phospholipids and lipoproteins, inhibits fungi growth, damages the capsid of viruses, and upsets the reproductive cycle by disrupting the virus-to-cell contact with peroxidation. ${ }^{12}$ Oxygen-ozone therapy causes an increase in the rate of red blood cell glycolysis, causing the stimulation of 2,3-diphosphoglycerate, which leads to an increase in oxygen released to the tissues. ${ }^{13}$ It also causes a reduction in NADH and helps to oxidize cytochrome C. ${ }^{14}$ It increases the production of interferon, tumor necrosis factor, and interleukin-2, activating the immune system. ${ }^{15}$ Nowadays, the bactericidal effects of ozone therapy have been studied in detail and have been extensively reported in hepatitis B, diabetes mellitus, degenerative diseases, ischemic diseases, and so forth. ${ }^{16-18}$ In addition, many studies have also reported on available scientific evidence concerning the beneficial properties of ozone therapy of pain, resulting in ozone therapy being widely used in pain management. ${ }^{19,20}$ However some complications of oxygen-ozone therapy still exist, such as headache pain, pneumocephalus, and cardiopulmonary arrest. ${ }^{21,22}$

At present, the efficacy and safety of ozone autohemotherapy in PHN remains unclear. Therefore, the objective of this study was to investigate the effectiveness and safety of ozone autohemotherapy combined with pharmacological therapy in patients with PHN.

\section{Subjects and methods Study design, setting, and selection of patients}

A total of 120 patients with PHN were recruited from the Affiliated Traditional Chinese Medicine Hospital of Southwest Medical University from May 2015 to March 2017. According to the inclusion and exclusion criteria, $98 \mathrm{PHN}$ patients were ultimately enrolled in this study. A randomnumber method using a computerized number generator (version 8.3; SAS Institute Inc., Cary, NC, USA) was used to randomly divide all included patients into the pharmacological therapy group and the ozone therapy group (49 patients in each group). The inclusion criteria were as follows: 1) PHN and suffering from severe pain for more than 1 month, 2) age $>18$ years, 3) Visual Analog Scale (VAS) score $>4$ points, and 4) ability to communicate in the language and follow the instructions. The exclusion criteria were as follows: 1) presence of other NP, 2) mental illness or central nervous system disease, and 3 ) malignant tumors. The enrolled patients signed written informed consent and this study was approved by the Medical Ethical Committee of Affiliated Traditional Chinese Medicine Hospital of Southwest Medical University, Luzhou, Sichuan Province, People's Republic of China. The registration had been finished (No. researchregistry2767).

\section{Therapeutic method}

Patients in the pharmacological therapy group accepted pharmacological therapy for only 2 weeks, and the patients in the ozone autohemotherapy group were administered ozone autohemotherapy combined with pharmacological therapy for 2 weeks. The pharmacological therapy was performed with diclofenac $75 \mathrm{mg} /$ day, pregabalin $300 \mathrm{mg}$ /day, and cobamamide $1 \mathrm{mg}$ /day. Ozone autohemotherapy was performed as follows: In the morning, $200 \mathrm{~mL}$ blood was collected via the median cubital vein, the concentration of medical ozone was set as $30 \mu \mathrm{g} / \mathrm{mL}$ using an ozone medical apparatus (Green Environmental Protection Equipment Co., Ltd., Chengdu, Sichuan Province, China), $40 \mathrm{~mL}$ medical ozone was incubated in $200 \mathrm{~mL}$ autologous blood for 3-5 minutes, and the incubated blood was then transfused back into the patient within 15 minutes, three times per week, for 2 weeks.

\section{Outcome measurements VAS}

The VAS was a 100-mm horizontal line labeled no pain at one end and worst imaginable pain at the other end. The patients were asked to mark on this line where the intensity of the pain existed. The distance from no pain to the patients' mark numerically quantifies the pain. The VAS is a simple and efficient method that correlates well with other reliable methods.

\section{McGill Pain Questionnaire (MPQ)}

The MPQ has three parts: the first assesses pain quality and yields a sensory score (sum of 11 adjectives: throbbing, shooting, stabbing, sharp, cramping, gnawing, hot burning, aching, heavy, tender, and splitting, each rated on an intensity 
scale with $0=$ none, $1=$ mild, $2=$ moderate, and $3=$ severe $)$, an affective score (sum of four adjectives, tiring-exhausting, sickening, fearful, and punishing-cruel related on the same intensity scale), and a total score (sum of the sensory and effective scores). The second part of the short form (SF)MPQ consists of a 100-mm VAS of pain intensity that patients used to rate their pain during the preceding week. The third part of the SF-MPQ is a measure of present pain intensity (PPI) using a 6 -point scale $(0=$ none, $1=$ mild, $2=$ discomfort, $3=$ distressing, $4=$ horrible, and $5=$ excruciating).

\section{Patients' Global Impression of Change (PGIC)}

The evaluation of relief level of pain symptoms was measured by the PGIC score. It is a 4-point numerical rating scale ( $1=$ obvious improvement, $2=$ slight improvement, $3=$ no change, $4=$ pain is more intense).

\section{World Health Organization Quality of Life (WHOQOL-BREF)}

The evaluation of quality of life was measured using five selected items of the WHOQOL-BREF, which conveys good reliability and validity for the assessment of quality of life in individuals. Respondents are asked to rate their satisfaction with overall quality of life and four different life domains (ie, health, daily activities, relationships, and living conditions) on a 5-point response scale ranging from very dissatisfied to very satisfied. The higher scores indicate higher quality of life.

\section{Statistical analysis}

All data were analyzed using SPSS 19.0 (IBM Corporation, Armonk, NY, USA) and GraphPad Prism 5.0 (GraphPad Software, Inc., La Jolla, CA, USA). The data were presented as the mean $\pm \mathrm{SD}$ or $\mathrm{n}(\%)$. The independent-samples $t$-test was used for statistical analysis of the continuous data, and the Chi-squared test was used for statistical analysis of the categorical data. The repeated-measures analysis of variance (ANOVA) test was used to compare data between the two groups before and after treatment. A $P$-value $<0.05$ was considered to represent a statistically significant difference.

\section{Results}

A total of 120 PHN patients initially entered the study (Figure 1). Of these patients, 12 patients did not meet the inclusion criteria and 10 patients met the exclusion criteria. Therefore, 98 PHN patients were randomly divided into the pharmacological therapy group and the ozone autohemotherapy group. There were four PHN patients who were lost to follow-up in the pharmacological therapy group and three PHN patients who were lost to follow-up in the ozone autohemotherapy group; therefore, 45 PHN patients were enrolled in the pharmacological therapy group and 46 PHN patients in the ozone autohemotherapy group, as shown in Figure 1. In addition, there were no statistically significant differences in the characteristics between groups at baseline $(P>0.05)$, as shown in Table 1 .

In this study, we examined the change in VAS score, the $50 \%$ VAS reduction of the initial value, and MPQ, PGIC, and WHOQOL-BREF scores from both groups before and after treatment. The results showed that compared with before therapy, there were significant improvements in the VAS, MPQ, PGIC, and WHOQOL-BREF scores after therapy $(P<0.05)$. Moreover, compared with the pharmacological therapy group, the scores of patients in the ozone autohemotherapy group were significantly improved in the VAS, MPQ, PGIC, and WHOQOL-BREF and in the 50\% VAS reduction of the initial value after therapy $(P<0.05)$, as shown in Tables $2-6$.

Finally, in this study, we also observed adverse reactions, including nausea, vomiting, dizziness, somnolence, palpitations, chest tightness, bleeding, infection, and allergy, in both groups after treatment. The results showed that the adverse effects experienced in both groups were not statistically different after treatment, as shown in Table 7.

\section{Discussion}

PHN is a sequela of herpes zoster virus infection and is an NP. Age and duration of disease are potential risk factors. ${ }^{23}$ When herpes zoster infection is present, complications, especially PHN, can develop and are associated with substantial morbidity among elderly patients. For patients with herpes zoster, PHN is a common complication and affects the life quality of these patients. ${ }^{24} \mathrm{PHN}$ is frequently accompanied by severe pain; however, the underlying mechanism of this complication remains unclear. In addition, until now, available therapy for PHN is still not ideal.

At present, clinical therapy of the disease consists of comprehensive measures to compensate for the shortcomings of a single treatment. In this study, ozone autohemotherapy combined with pharmacological therapy was used to treat PHN, and results showed that this combination treatment resulted in more significant improvements compared with pharmacological therapy alone in the VAS, MPQ, PGIC, and WHOQOL-BREF scores and in 50\% VAS reduction of the initial value after treatment, which could improve pain symptoms and quality of life. In addition, ozone autohemotherapy combined with pharmacological therapy did 


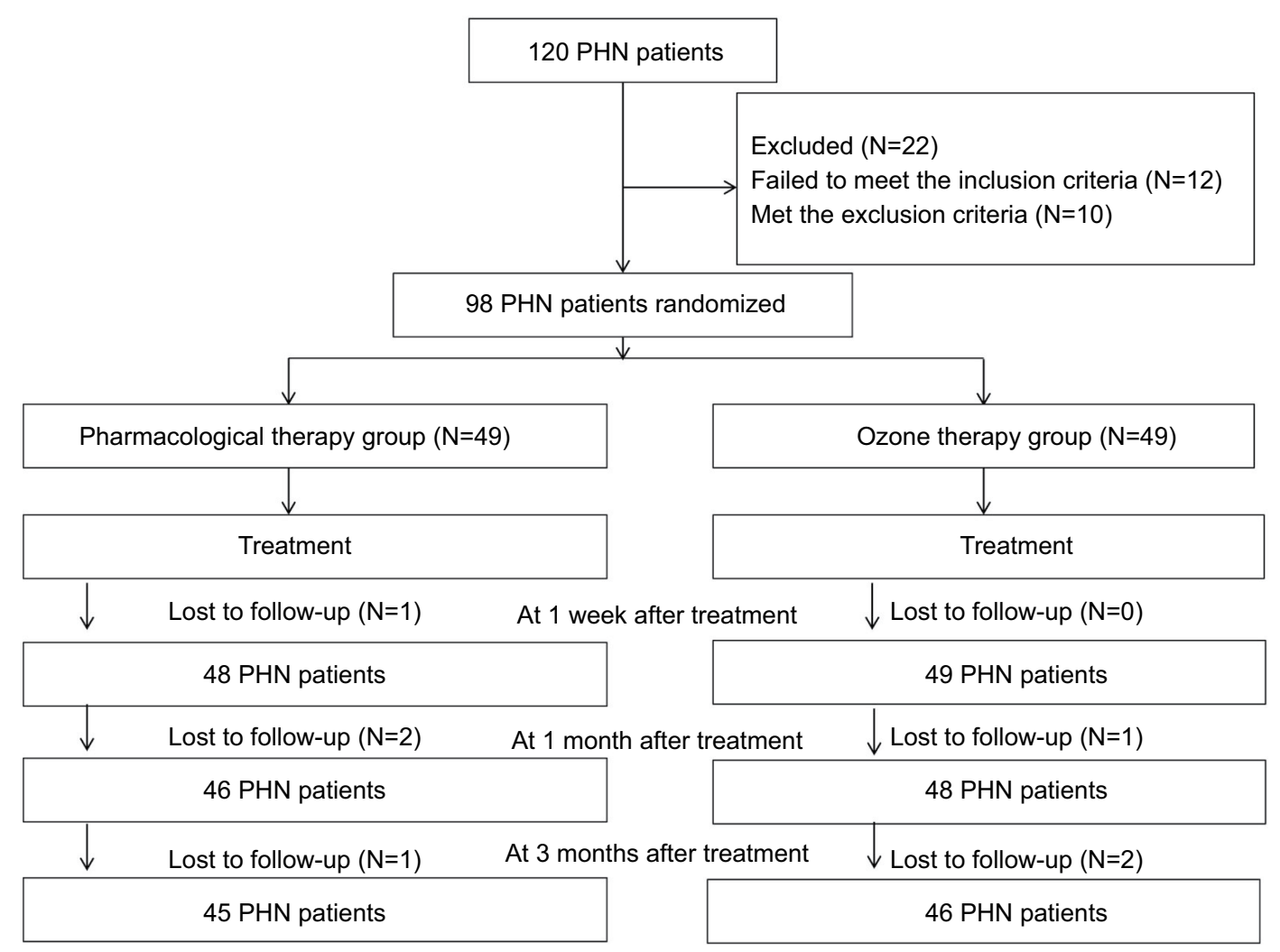

Figure I Flowchart of this study.

Abbreviation: $\mathrm{PHN}$, postherpetic neuralgia.

Table I Characteristics of both groups at baseline

\begin{tabular}{|c|c|c|c|}
\hline Characteristic & $\begin{array}{l}P \text { group } \\
(n=45)\end{array}$ & $\begin{array}{l}O \text { group } \\
(n=46)\end{array}$ & $P$-value \\
\hline Age (years) ${ }^{\mathrm{a}}$ & $62.3 \pm 11.2$ & $63.6 \pm 10.5$ & 0.567 \\
\hline Gender $^{\mathrm{b}}$ & $25 / 20$ & $28 / 18$ & 0.457 \\
\hline Weight (kg) & $58.4 \pm 8.5$ & $59.2 \pm 9.4$ & 0.854 \\
\hline \multicolumn{4}{|l|}{ Herpes zoster site } \\
\hline Intercostal region & 30 & 35 & 0.834 \\
\hline Neck and arm region & 3 & 5 & 0.823 \\
\hline Face region & 8 & 6 & 0.754 \\
\hline Lumbosacral region & 4 & 5 & 0.678 \\
\hline Duration of PHN (months) ${ }^{\mathrm{a}}$ & $2.8 \pm 1.5$ & $2.9 \pm 1.6$ & 0.821 \\
\hline Cardiac disease $^{\mathrm{b}}$ & $24 / 45$ & $25 / 46$ & 0.659 \\
\hline Pulmonary disease ${ }^{b}$ & $26 / 45$ & $24 / 46$ & 0.547 \\
\hline Liver and renal diseases ${ }^{\mathrm{b}}$ & $8 / 45$ & $8 / 46$ & 0.625 \\
\hline Metabolism and nutrition disorders ${ }^{\mathrm{b}}$ & $6 / 45$ & $7 / 46$ & 0.689 \\
\hline
\end{tabular}

Notes: Data are presented as mean \pm SD or $\mathrm{n} . \mathrm{P}$ group $=$ pharmacological therapy group; $O$ group $=$ ozone therapy group. $P<0.05$ was considered statistically significant. ${ }^{a}$ Independent-samples $t$-test. ${ }^{b}$ Chi-square test.

Abbreviation: $\mathrm{PHN}$, postherpetic neuralgia.

not increase adverse reactions after treatment. Therefore, ozone autohemotherapy combined with pharmacological therapy was superior to isolated pharmacological therapy in the treatment of PHN and was an effective and safe way to relieve PHN.
Table 2 VAS scores of both groups before and after treatment

\begin{tabular}{lllll}
\hline Group & Before & $\begin{array}{l}\text { I week } \\
\text { after }\end{array}$ & $\begin{array}{l}\text { I month } \\
\text { after }\end{array}$ & $\begin{array}{l}3 \text { months } \\
\text { after }\end{array}$ \\
\hline P group $(n=45)$ & $6.2 \pm 1.3$ & $5.0 \pm 1.2^{\mathrm{a}}$ & $3.1 \pm 1 . I^{\mathrm{a}}$ & $1.8 \pm 0.8^{\mathrm{a}}$ \\
O group $(\mathrm{n}=46)$ & $6.5 \pm 1.4$ & $4.8 \pm 1 . \mathrm{I}^{\mathrm{a}}$ & $1.8 \pm 1 . \mathrm{I}^{\mathrm{a}, \mathrm{b}}$ & $0.9 \pm 0.5^{\mathrm{a}, \mathrm{b}}$ \\
\hline
\end{tabular}

Notes: Data are presented as mean \pm SD. $P$ group $=$ pharmacological therapy group; $\bigcirc$ group $=$ ozone therapy group. $P<0.05$ was considered statistically significant.

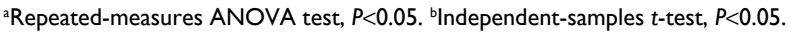

Abbreviation: VAS, Visual Analog Scale.

Table 3 VAS reduction of $50 \%$ of the initial value in both groups after treatment

\begin{tabular}{lllll}
\hline Group & Before & $\begin{array}{l}\text { I week } \\
\text { after }\end{array}$ & $\begin{array}{l}\text { I month } \\
\text { after }\end{array}$ & $\begin{array}{l}\text { 3 months } \\
\text { after }\end{array}$ \\
\hline P group $(n=45)$ & 0 & 8 & 26 & 40 \\
O group $(n=46)$ & 0 & 13 & $4 I^{\text {a }}$ & 43 \\
\hline
\end{tabular}

Notes: Data are presented as $n$. $P$ group $=$ pharmacological therapy group; $O$ group $=$ ozone therapy group. $P<0.05$ was considered statistically significant. ${ }^{a} \mathrm{Chi}$-squared test, $P<0.05$.

Abbreviation: VAS, Visual Analog Scale.

Some studies have reported that PHN is related to several mechanisms. For example, PHN is a peripheral neuropathy, primarily presented as peripheral nerve inflammation and abnormal conduction after nerve injury. The anatomy of the 
Table 4 SF-MPQ score of both groups before and after treatment

\begin{tabular}{|c|c|c|c|c|c|c|c|c|}
\hline \multirow[t]{2}{*}{ SF-MPQ } & \multicolumn{4}{|c|}{$P$ group $(n=45)$} & \multicolumn{4}{|c|}{ O group $(n=46)$} \\
\hline & TO & TI & T2 & T3 & TO & TI & T2 & T3 \\
\hline Sensory score & $5.7 \pm 0.8$ & $4.6 \pm 0.7^{a}$ & $3.7 \pm 0.5^{\mathrm{a}}$ & $2.8 \pm 0.6^{a}$ & $5.7 \pm 0.8$ & $4.4 \pm 0.5^{\mathrm{a}}$ & $2.6 \pm 0.4^{\mathrm{a}, \mathrm{b}}$ & $1.6 \pm 0.5^{\mathrm{a}, \mathrm{b}}$ \\
\hline Effective score & $4.2 \pm 1.0$ & $3.2 \pm 0.9^{a}$ & $2.9 \pm 0.9^{a}$ & $1.8 \pm 0.8^{a}$ & $4.3 \pm 0.9$ & $3.0 \pm 0.8^{\mathrm{a}}$ & $1.5 \pm 0.6^{\mathrm{a}, \mathrm{b}}$ & $0.9 \pm 0.5^{\mathrm{a}, \mathrm{b}}$ \\
\hline Total score & $9.1 \pm 1.1$ & $7.5 \pm 1.0^{\mathrm{a}}$ & $6.2 \pm 0.9^{\mathrm{a}}$ & $4.5 \pm 0.7^{\mathrm{a}}$ & $9.1 \pm 1.1$ & $7.4 \pm 0.9^{\mathrm{a}}$ & $4.3 \pm 0.8^{\mathrm{a}, \mathrm{b}}$ & $2.5 \pm 0.5^{\mathrm{a}, \mathrm{b}}$ \\
\hline VAS (mm) & $68.2 \pm 7.2$ & $52.4 \pm 6.5^{\mathrm{a}}$ & $32.5 \pm 5.2^{\mathrm{a}}$ & $18.3 \pm 4.5^{\mathrm{a}}$ & $65.3 \pm 8.1$ & $47.2 \pm 5.6^{\mathrm{a}}$ & $19.2 \pm 5.2^{\mathrm{a}, \mathrm{b}}$ & $9.4 \pm 3.2^{\#}$ \\
\hline PPI & $4.5 \pm 0.9$ & $3.4 \pm 0.7^{\mathrm{a}}$ & $2.5 \pm 0.6^{a}$ & $1.7 \pm 0.7^{\mathrm{a}}$ & $4.6 \pm 0.8$ & $3.2 \pm 0.8^{\mathrm{a}}$ & $1.8 \pm 0.6^{\mathrm{a}, \mathrm{b}}$ & $0.8 \pm 0.5^{* \#}$ \\
\hline
\end{tabular}

Notes: Data are presented as mean \pm SD. $P$ group = pharmacological therapy group; $O$ group = ozone therapy group; T0= before treatment; $T I=I$ week after treatment;

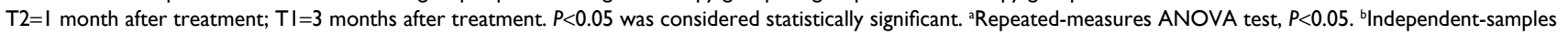
$t$-test, compared with $P$ group, $P<0.05$.

Abbreviations: MPQ, McGill Pain Questionnaire; VAS, Visual Analog Scale; PPI, present pain intensity.

Table 5 PGIC score of both groups before and after treatment

\begin{tabular}{lllll}
\hline Group & Before & $\begin{array}{l}\text { I week } \\
\text { after }\end{array}$ & $\begin{array}{l}\text { I month } \\
\text { after }\end{array}$ & $\begin{array}{l}\text { 3 months } \\
\text { after }\end{array}$ \\
\hline$P$ group $(n=45)$ & - & $3.2 \pm 0.8$ & $2.4 \pm 0.9^{\mathrm{a}}$ & $1.2 \pm 0.7^{\mathrm{a}}$ \\
O group $(\mathrm{n}=46)$ & - & $3.1 \pm 0.7$ & $1.6 \pm 0.8^{\mathrm{a}, \mathrm{b}}$ & $0.7 \pm 0.4$ \\
\hline
\end{tabular}

Notes: Data are presented as mean \pm SD. P group $=$ pharmacological therapy group; $O$ group $=$ ozone therapy group. $P<0.05$ was considered statistically significant. aRepeated-measures ANOVA test, $P<0.05$. 'Independent-samples $t$-test, $P<0.05$. Abbreviation: PGIC, Patients' Global Impression of Change.

Table 6 WHOQOL-BREF score of both groups before and after treatment

\begin{tabular}{lllll}
\hline Group & Before & $\begin{array}{l}\text { I week } \\
\text { after }\end{array}$ & $\begin{array}{l}\text { I month } \\
\text { after }\end{array}$ & $\begin{array}{l}\text { 3 months } \\
\text { after }\end{array}$ \\
\hline P group $(n=45)$ & $0.8 \pm 0.6$ & $1.5 \pm 0.7^{\mathrm{a}}$ & $2.8 \pm 0.5^{\mathrm{a}}$ & $3.6 \pm 0.4^{\mathrm{a}}$ \\
O group $(\mathrm{n}=46)$ & $0.9 \pm 0.5$ & $1.8 \pm 0.6^{\mathrm{a}}$ & $3.4 \pm 0.6^{\mathrm{a}, \mathrm{b}}$ & $4.2 \pm 0.5^{\mathrm{a}, \mathrm{b}}$ \\
\hline
\end{tabular}

Notes: Data are presented as the mean \pm SD. $P$ group $=$ pharmacological therapy group; $O$ group $=$ ozone therapy group. $P<0.05$ was considered statistically

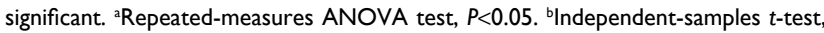
$P<0.05$.

Abbreviation: WHOQOL, World Health Organization Quality of Life.

Table 7 Adverse reactions observed in both groups after treatment

\begin{tabular}{llll}
\hline Adverse reaction & $\begin{array}{l}\text { P group } \\
(\mathbf{n = 4 5 )}\end{array}$ & $\begin{array}{l}\text { O group } \\
(\mathbf{n = 4 6 )}\end{array}$ & P-value \\
\hline Nausea $^{\mathrm{a}}$ & $4 / 45$ & $5 / 46$ & 0.954 \\
Vomiting $^{\mathrm{a}}$ & $2 / 45$ & $2 / 46$ & 0.869 \\
Dizziness $^{\mathrm{a}}$ & $3 / 45$ & $4 / 46$ & 0.872 \\
Somnolence $^{\mathrm{a}}$ & $4 / 45$ & $5 / 46$ & 1.000 \\
Palpitation $^{\mathrm{a}}$ & $2 / 45$ & $3 / 46$ & 0.925 \\
Chest tightness $^{\mathrm{a}}$ & $3 / 45$ & $4 / 46$ & 0.872 \\
Bleeding $^{\mathrm{a}}$ & $0 / 46$ & $0 / 46$ & 1.000 \\
Infection $^{\mathrm{a}}$ & $2 / 45$ & $1 / 46$ & 0.925 \\
Allergy $^{\mathrm{a}}$ & $\mathrm{I} / 45$ & $\mathrm{I} / 46$ & 0.936 \\
\hline
\end{tabular}

Notes: Data are presented as $n$. $P$ group $=$ pharmacological therapy group; $O$ group $=$ ozone therapy group. $P<0.05$ was considered statistically significant. ${ }^{2}$ Chi-square test.

primary afferent receptor is complete; however, the state is kept as abnormally hyperactive, which plays an important role in causing pain and maintaining abnormal pain ${ }^{25}$; this can be described as an "irritant receptor." In addition, PHN is described as a central nervous system (CNS) abnormality (CNS sensitization), and abnormal pain and generalized $\mathrm{C}$ fibrosis are present at the same time; the completed and low-threshold $A \beta$ fiber enters into the superficial layer of the dorsal horn of the spinal cord, directly connected with the two-stage pain-transmitting neuron, causing the pain. ${ }^{26,27}$ Moreover, for PHN, in the areas with obvious sensory deficits but no abnormal pain, there is persistent pain, or loss of sensory pain, which can be described as "afferent nerve block." 28 Finally, some studies have also shown that PHN is related to mental factors, as stress and anxiety can also lead to PHN. ${ }^{29}$

Although there are many methods of treating PHN with comprehensive measures, there are few clinical studies on this method. Ozone autohemotherapy has been a basic and clinical study for nearly 40 years and has become a relatively mature method of clinical treatment. Nowadays, ozone autohemotherapy is reported as being mainly used for the therapy of viral hepatitis, hyperlipidemia, stroke, rheumatic diseases, insomnia, and cancer. However, the effect of ozone autohemotherapy on PHN remains unclear. In this study, ozone autohemotherapy was used to treat PHN, and an obvious clinical effect was achieved. The reasons for this clinical effect may be related to the following mechanisms: 1) Medical ozone has a strong bactericidal effect, and specific concentration of medical ozone can inhibit the growth and reproduction of herpes virus and promote the phagocytosis of leukocytes for herpes virus; ${ }^{30,31}$ 2) medical ozone can increase the oxygencarrying ability and erythrocyte rheology of red blood cells, increase the oxygen supply for tissues and cells, improve the microcirculation in damaged nerve and skin tissue, and promote the repair of local nerves and tissue; ${ }^{32} 3$ ) medical ozone mixed with blood can produce hydrogen peroxide $\left(\mathrm{H}_{2} \mathrm{O}_{2}\right)$, which can be as an important messenger, activate the body's immune system, initiate a series of chemical reactions, induce the production of interleukin and interferon and other 
cytokines to activate and regulate the immune system function, and, finally, restore the normal functioning of the thalamus for the pain loop; ${ }^{33} 4$ ) ozone autohemotherapy can bring a pleasant sensation to the person, relieve the patient's fatigue and depression, and improve physical strength and mental stability. ${ }^{34}$ In addition, reactive oxygen species (ROS) and lipid oxidative products (LOPs), believed to be involved in the biological progress of ozone, are produced immediately after ozone is dissolved in biological water (plasma, lymph, urine, interstitial fluid, etc.). ${ }^{20}$ ROS and LOPs have been reported to activate nuclear transcriptional factors, such as nuclear factorerythroid 2-related factor 2, so as to alleviate pain. ${ }^{35,36}$ Finally, one study also speculated that ozone directly or indirectly acted on transmembrane proteins, intracellular cascades, and nuclear transcriptions to alleviate pain. ${ }^{37}$ Therefore, this clinical effect of ozone autohemotherapy in PHN is a complicated process, and its specific mechanisms require further study.

In conclusion, the findings of this study demonstrated that ozone autohemotherapy combined with pharmacological therapy was superior to isolated pharmacological therapy in the treatment of PHN and was an effective and safe way to relieve $\mathrm{PHN}$.

\section{Disclosure}

The authors report no conflicts of interest in this work.

\section{References}

1. Mallick-Searle T, Snodgrass B, Brant JM. Postherpetic neuralgia: epidemiology, pathophysiology, and pain management pharmacology. J Multidiscip Healthc. 2016;9:447-454.

2. Deer TR, Mekhail N, Provenzano D, et al. The appropriate use of neurostimulation of the spinal cord and peripheral nervous system for the treatment of chronic pain and ischemic diseases: the Neuromodulation Appropriateness Consensus Committee. Neuromodulation. 2014;17(6):515-550.

3. Hadley GR, Gayle JA, Ripoll J, et al. Post-herpetic neuralgia: a review. Curr Pain Headache Rep. 2016;20(3):17.

4. Keating GM, Shingles KGM. Shingles (herpes zoster) vaccine (Zos$\left.\operatorname{tavax}\left({ }^{\circledR}\right)\right)$ : a review in the prevention of herpes zoster and postherpetic neuralgia. BioDrugs. 2016;30(3):243-254.

5. Pickering G, Leplege A. Herpes zoster pain, postherpetic neuralgia, and quality of life in the elderly. Pain Pract. 2011;11(4):397-402.

6. Cunningham AL, Dworkin RH. The management of post-herpetic neuralgia. BMJ. 2000;321(7264):778-779.

7. Bricout H, Perinetti E, Marchettini P, et al. Burden of herpes zosterassociated chronic pain in Italian patients aged 50 years and over (2009-2010): a GP-based prospective cohort study. BMC Infect Dis. 2014; 14:637.

8. Bouhassira D, Chassany O, Gaillat J, et al. Patient perspective on herpes zoster and its complications: an observational prospective study in patients aged over 50 years in general practice. Pain. 2012;153(2):342-349.

9. Wollina U, Machetanz J. Herpes zoster and postherpetic neuralgia. Hautarzt. 2016;67(8):653-665.

10. Elvis AM, Ekta JS. Ozone therapy: A clinical review. J Nat Sci Biol Med. 2011;2(1):66-70.
11. Nogales CG, Ferrari PH, Kantorovich EO, Lage-Marques JL. Ozone therapy in medicine and dentistry. $J$ Contemp Dent Pract. 2008;9(4):75-84.

12. Đuričić D, Valpotić H, Samardžija M. Prophylaxis and therapeutic potential of ozone in buiatrics: Current knowledge. Anim Reprod Sci. 2015;159:1-7.

13. Artis AS, Aydogan S, Sahin MG. The effects of colorectally insufflated oxygen-ozone on red blood cell rheology in rabbits. Clin Hemorheol Microcirc. 2010;45(2-4):329-336.

14. Aydos TR, Başar MM, Kul O, et al. Effects of ozone therapy and taurine on ischemia/reperfusion-induced testicular injury in a rat testicular torsion model. Turk J Med Sci. 2014;44(5):749-755.

15. Pendino KJ, Shuler RL, Laskin JD, Laskin DL. Enhanced production of interleukin-1, tumor necrosis factor-alpha, and fibronectin by rat lung phagocytes following inhalation of a pulmonary irritant. Am J Respir Cell Mol Biol. 1994;11(3):279-286.

16. Bocci V, Zanardi I, Huijberts MS, Travagli V. Diabetes and chronic oxidative stress. A perspective based on the possible usefulness of ozone therapy. Diabetes Metab Syndr. 2011;5(1):45-49.

17. Braidy N, Izadi M, Sureda A, et al. Therapeutic relevance of ozone therapy in degenerative diseases: Focus on diabetes and spinal pain. J Cell Physiol. 2018;233(4):2705-2714.

18. Bocci V, Travagli V, Zanardi I. May oxygen-ozone therapy improves cardiovascular disorders? Cardiovasc Hematol Disord Drug Targets. 2009;9(2):78-85.

19. Muto M, Giurazza F, Silva RP, Guarnieri G. Rational approach, technique and selection criteria treating lumbar disk herniations by oxygenozone therapy. Interv Neuroradiol. 2016;22(6):736-740.

20. Bocci V, Borrelli E, Zanardi I, Travagli V. The usefulness of ozone treatment in spinal pain. Drug Des Devel Ther. 2015;9:2677-2685.

21. Beyaz SG, Altaş C, Sayhan H. Cardiopulmonary arrest and pneumoencephaly developing after epidural oxygen-ozone mixture therapy. Anesth Essays Res. 2018;12(1):285-287.

22. Toman H, Özdemir U, Kiraz HA, Lüleci N. Severe headache following ozone therapy: Pneumocephalus. Agri. 2017;29(3):132-136.

23. Jeon YH, Zoster H. Herpes zoster and postherpetic neuralgia: practical consideration for prevention and treatment. Korean J Pain. 2015;28(3):177-184.

24. Kawai K, Rampakakis E, Tsai TF, et al. Predictors of postherpetic neuralgia in patients with herpes zoster: a pooled analysis of prospective cohort studies from North and Latin America and Asia. Int J Infect Dis. 2015;34:126-131.

25. Oaklander AL. Mechanisms of pain and itch caused by herpes zoster (shingles). J Pain. 2008;9(1 Suppl. 1):10-18.

26. Zhang Q, Peng L, Zhang D. Minocycline may attenuate postherpetic neuralgia. Med Hypotheses. 2009;73(5):744-745.

27. Pappagallo M, Oaklander AL, Quatrano-Piacentini AL, Clark MR, Raja SN. Heterogenous patterns of sensory dysfunction in postherpetic neuralgia suggest multiple pathophysiologic mechanisms. Anesthesiology. 2000;92(3):691-698.

28. Kim K, Jo D, Kim E. Pulsed radiofrequency to the dorsal root ganglion in acute herpes zoster and postherpetic neuralgia. Pain Physician. 2017;20(3):E411-E418.

29. Lionis CD, Vardavas CI, Symvoulakis EK, Papadakaki MG, et al. Measuring the burden of herpes zoster and post herpetic neuralgia within primary care in rural Crete, Greece. BMC Fam Pract. 2011;12:136.

30. Nishimura $\mathrm{H}$. Analysis of bactericidal material generated by electrical devices advertising bactericidal ability against bacteria on the agar gel plates. Kansenshogaku Zasshi. 2012;86(6):723-733.

31. Avcı S, Büyükcam F, Demir ÖF, Özkan S. Anton syndrome during oxygen-ozone therapy. Am J Emerg Med. 2015;33(6):856.e1-2.

32. Bocci V. Autohaemotherapy after treatment of blood with ozone. A reappraisal. J Int Med Res. 1994;22(3):131-144.

33. Gracer RI, Bocci V. Can the combination of localized "proliferative therapy" with "minor ozonated autohemotherapy" restore the natural healing process? Med Hypotheses. 2005;65(4):752-759. 
34. Mokoena ML, Harvey BH, Viljoen F, Ellis SM, Brink CB. Ozone exposure of Flinders Sensitive Line rats is a rodent translational model of neurobiological oxidative stress with relevance for depression and antidepressant response. Psychopharmacology. 2015;232(16):2921-2938.

35. Fattori V, Pinho-Ribeiro FA, Borghi SM, et al. Curcumin inhibits superoxide anion-induced pain-like behavior and leukocyte recruitment by increasing $\mathrm{Nrf} 2$ expression and reducing NF- $\mathrm{KB}$ activation. Inflamm Res. 2015;64(12):993-1003.
36. Jang M, Lee MJ, Choi JH, et al. Ginsenoside Rb1 attenuates acute inflammatory nociception by inhibition of neuronal ERK phos-

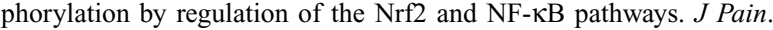
2016;17(3):282-297.

37. Luo WJ, Yang F, Yang F, Sun W, et al. Intervertebral foramen injection of ozone relieves mechanical allodynia and enhances analgesic effect of gabapentin in animal model of neuropathic pain. Pain Physician. 2017;20(5):E673-E685

\section{Publish your work in this journal}

The Journal of Pain Research is an international, peer reviewed, open access, online journal that welcomes laboratory and clinical findings in the fields of pain research and the prevention and management of pain. Original research, reviews, symposium reports, hypothesis formation and commentaries are all considered for publication.

\section{Dovepress}

The manuscript management system is completely online and includes a very quick and fair peer-review system, which is all easy to use. Visit http://www.dovepress.com/testimonials.php to read real quotes from published authors. 